\title{
a-Actinin-4 promotes metastasis in gastric cancer
}

\author{
Xin Liu and Kent-Man Chu
}

Metastasis increases the mortality rate of gastric cancer, which is the third leading cause of cancer-associated deaths worldwide. This study aims to identify the genes promoting metastasis of gastric cancer (GC). A human cell motility PCR array was used to analyze a pair of tumor and non-tumor tissue samples from a patient with stage IV GC (T3N3M1). Expression of the dysregulated genes was then evaluated in GC tissue samples $(n=10)$ and cell lines $(n=6)$ via qPCR. Expression of $a$-actinin-4 (ACTN4) was validated in a larger sample size $(n=47)$ by qPCR, western blot and immunohistochemistry. Knockdown of ACTN4 with specific siRNAs was performed in GC cells, and adhesion assays, transwell invasion assays and migration assays were used to evaluate the function of these cells. Expression of potential targets of ACTN4 were then evaluated by qPCR. Thirty upregulated genes (greater than twofold) were revealed by the PCR array. We focused on ACTN4 because it was upregulated in 6 out of 10 pairs of tissue samples and 5 out of 6 GC cell lines. Further study indicated that ACTN4 was upregulated in 22/32 pairs of tissue samples at stage III \& IV $(P=0.0069)$. Knockdown of ACTN4 in GC cells showed no significant effect on cell proliferation, but significantly increased cell-matrix adhesion, as well as reduced migration and invasion of AGS, MKN7 and NCI-N87 cells. We found that NF- $K \mathrm{~B}$ was downregulated in GC with the knockdown of ACTN4. In conclusion, this is the first study to indicate that ACTN4 is significantly upregulated in patients with metastatic GC. ACTN4 reduces cell adhesion and enhances migration and invasion of GC cells and may therefore be a novel therapeutic target for GC.

Laboratory Investigation (2017) 97, 1084-1094; doi:10.1038/labinvest.2017.28; published online 5 June 2017

Gastric cancer (GC) is the third leading cause of cancer-associated deaths worldwide. ${ }^{1}$ Moreover, it has been predicted that the mortality rate of GC will rise from the 15 th to the 10th most common cause of death globally by $2030 .^{2}$ About $70 \%$ of the GC cases occur in eastern Asia, with the highest morbidity in China, Korea, and Japan. In general, the 5 -year survival rate for patients at the early stage of GC is $>90 \%$. However, the chance for survival drops markedly to $<25 \%$ for advanced stage disease with metastasis. ${ }^{3,4}$ The preferred sites of metastatic GC include lymph nodes, liver and peritoneum..$^{5,6}$

Metastasis of cancer cells is a complex, multi-step process. Generally, it involves cancer cells acquiring the capability to invade and disseminate from their original location. These cells survive in circulation and colonize in secondary organs at which they form new tumors. ${ }^{7}$ Numerous genes have important roles in these processes. For example, genes for chemotaxis and growth factors contribute to invasion. ${ }^{8,9}$ Genes for cell adhesion, protrusion, or movement lead to intravasation and migration. ${ }^{10}$ Genes encoding receptors and proteases are involved in extravasation. ${ }^{11,12}$
Previous studies have indicated that numerous, complex gene interactions are necessary for metastasis, including vascular endothelium growth factor receptor, matrix metallopeptidase (MMP), and members of the PI3K-Akt and WntNotch signaling pathways. ${ }^{13-20}$ However, the mechanism of GC metastasis remains unclear; hence, the aim of this study was to identify genes promoting metastasis of GC.

In this paper, $\alpha$-actinin-4 (ACTN4) is identified as a key player in GC metastasis. ACTN4 is a member of the $\alpha$-actinin family, which belongs to the spectrin superfamily proteins. There are four isoforms of $\alpha$-actinin, and isoform 4 is 'non-muscle' $\alpha$-actinin. It predominantly localizes in the cytoplasmic region, ${ }^{21}$ and has multiple roles in non-muscle cells, including cellular protrusion, cell adhesion, and cellular motility. ${ }^{22,23}$ Functionally, $\alpha$-actinin is associated with microfilament bundles and tight junctions, where it is involved in cross-linking actin filaments and connecting actin to the cell membrane. Actinin is a component of the stress fiber and structural protein, ${ }^{24}$ and the overexpression of ACTN4 contributes to metastasis and/or chemoresistance in lung cancer, ovarian cancer, and colorectal cancer. ${ }^{25-27}$ As a result, we proposed that ACTN4 is a key factor in GC metastasis.

Department of Surgery, The University of Hong Kong, Queen Mary Hospital, Pokfulam, Hong Kong

Correspondence: Professor K-M Chu, MBBS, MSC, FRCS (Edin), FACS, FCSHK, FHKAM (Surgery), Department of Surgery, The University of Hong Kong, Queen Mary Hospital, Pokfulam 000, Hong Kong.

E-mail: chukm@hku.hk

Received 5 April 2016; revised 8 December 2016; accepted 16 January 2017 


\section{MATERIALS AND METHODS}

\section{Human Tissue Samples}

Forty-seven pairs of human GC and non-tumor tissue samples were collected directly after surgical resection at Queen Mary Hospital, Hong Kong. All of the tumor tissue samples were validated as malignant by an experienced pathologist. All of the samples were obtained with the participants' informed consent and none of the patients received preoperative treatment. All samples were immediately frozen in liquid nitrogen and stored at $-80^{\circ} \mathrm{C}$.

\section{Cell Lines and Cell Culture}

Human GC cell lines including AGS, NCI-N87 (ATCC, Rockville, MD, USA), MKN7, MKN45 (Riken, Japan) and BGC823, PAM82 (given by Beijing Institute of Cancer Research, China) were used in this study. Cells were cultivated in RPMI 1640 medium (Gibco BRL, Gaithersburg, MD, USA) supplemented with $10 \%$ heat-inactivated fetal bovine serum (FBS) (Gibco BRL, Grand Island, NY, USA). All cells were incubated at $37^{\circ} \mathrm{C}$ in a humidified incubator which contains $5 \% \mathrm{CO} 2$.

\section{Rna Extraction in Tissue Samples and Cell Lines}

About $20 \mathrm{mg}$ of each tissue sample or $10^{6}$ cells of each cell line were used for RNA extraction via RNeasy Mini Kit (Qiagen, Hilden, Germany) according to the manufacturer's instructions. The concentrations of all RNA samples were quantified by NanoDrop 1000 (Nanodrop, Wilmington, DE, USA). From each sample, $500 \mathrm{ng}$ of total RNA were utilized for reverse transcription (RT).

\section{$\mathbf{R t}^{2}$ Profiler $^{\mathrm{tm}}$ PCR Array for Human Cell Motility}

A pair of tumor and non-tumor tissue samples from a patient with GC (stage IV with metastasis, T3N3M1) was used for the PCR array. Total RNA was extracted as prescribed above and reverse-transcribed using $\mathrm{RT}^{2}$ First Strand Kit (Qiagen). The cDNAs was used for the PCR array using $\mathrm{RT}^{2}$ SYBR Green qPCR Mastermixes (Qiagen). This profiler is a pathwayfocused gene expression analysis. It contains 84 genes involved in cell movement, including cell adhesion, cellular projection, chemotaxis, proteases, and their inhibitors. By comparing gene profiles between tumor and non-tumor tissue samples, different gene expression profiles were established. Upregulation of the genes (greater than twofold) in tumor samples compared with non-tumor samples after normalization were chosen for further study.

\section{RT Quantitative PCR (qPCR)}

SYBR green RT quantitative PCR (RT qPCR) assay was used for mRNA quantification in tissue samples and cells. A total of $500 \mathrm{ng}$ of RNA from each tissue sample or cell line containing total RNA were polyadenylated by poly (A) polymerase and reverse-transcribed to cDNA using Omniscript RT Kit (Qiagen) according to the manufacturer's instructions. Real-time PCR was performed using miScript
SYBR Green PCR Kit (Qiagen). Specific primers for $\mathrm{qPCR}$ were provided by IDT (Singapore). QPCR was performed in ABI ViiA7 Real-time PCR system (Applied Biosystems, Waltham, MA, USA). The primers sequences are listed in supplementary Table 1. The expression of mRNAs was normalized to GAPDH using the $2^{-\Delta \Delta \mathrm{Ct}}$ method. The $\Delta \mathrm{Ct}$ was calculated by subtracting the $\mathrm{Ct}$ values of GAPDH from the $\mathrm{Ct}$ values of targets. The $\Delta \Delta \mathrm{Ct}$ was then calculated by subtracting $\Delta \mathrm{Ct}$ of non-tumor sample from $\Delta \mathrm{Ct}$ of the paired tumor sample. Fold changes in the targets were calculated by the equation $2^{-\Delta \Delta C t}$.

\section{Western Blots}

Cells were harvested and lysed by RIPA Buffer (Sigma Chemical, St Louis, MD, USA). Samples containing equal amounts of protein were separated by SDS-PAGE and electroblotted onto Immobilon-P Transfer Membrane (Applied Biosystems). The membrane was blocked with 5\% non-fat milk, followed by incubation with antibodies specific for anti-ACTN4 (1:1000, Abcam, Cambridge, UK) and anti$\beta$-actin (1:10 000, Cell Signaling Technology, Beverly, MA, USA), respectively. Blots were then incubated with goat antirabbit or anti-mouse secondary antibody conjugated to horseradish peroxidase (Amersham Pharmacia, Cleveland, $\mathrm{OH}$, USA) accordingly. The signals were captured by FUJI Medical X-Ray Film (Fuji, Japan) and developed by the FUJI system.

\section{Immunohistochemistry}

Tissue sections were obtained from tumor and non-tumor segment of patients with GC. Consecutive paraffin-embedded tissue sections of $5 \mu \mathrm{m}$ were dewaxed and dehydrated. The slides were incubated at $50{ }^{\circ} \mathrm{C}$ overnight, then soaked in xylene for 10 min three times, and immersed in $100 \%$ ethanol for $5 \mathrm{~min}, 95 \%$ ethanol for $5 \mathrm{~min}$, and 80 and $70 \%$ ethanol for $1 \mathrm{~min}$. After rehydration for $5 \mathrm{~min}$, the slides were boiled in citrate buffer ( $\mathrm{pH}$ 6.1, Target Retrieval Solution; Sigma, CA, USA) for $25 \mathrm{~min}$, rinsed with $1 \times \mathrm{PBS}$ for $5 \mathrm{~min}$, and treated with $3 \%$ hydrogen peroxide for $10 \mathrm{~min}$. After that, slides were placed flat on the bench top and sections were covered in a solution of rabbit antibody to ACTN4 (1:100 dilution; Abcam) at room temperature for $30 \mathrm{~min}$ and then covered with a solution of goat anti-rabbit (1:500) (Dako) for $30 \mathrm{~min}$, and finally in a solution of streptavidin-horseradish peroxidase (LSAB2 System; Dako) for $30 \mathrm{~min}$. Color was with the Substrate-Chromogen Solution (LSAB2 System; Dako) for $5 \mathrm{~min}$, and counter-stained with Mayer hematoxylin (Merck, Darmstadt, Germany) for $1 \mathrm{~min}$. Finally, the slides were dehydrated in 50,75 , and $100 \%$ ethanol for 5 min each, and sealed with mounting medium (CytosealTM 60 Thermo Scientific, Waltham, MA, USA).

\section{SiRNAs and Transfection}

Small interfering RNAs (TriFECTa RNAi Kit) targeting ACTN4 were purchased from Integrated DNA Technologies, 
(Coralville, USA) (Supplementary Table 2). A total of $5 \times 10^{4}$ cells were seeded into a 12 -well plate a day in advance of transfection and transfected with $20 \mathrm{~nm}$ siRNA or scrambled control using Hiperfect Transfection Reagent (Qiagen),

\section{Table 1 Dysregulated genes in human cell motility profiler}

\begin{tabular}{llcc}
\hline Symbol & Full name & GenBank & T/N \\
\hline Cell adhesion & & \\
ACTN1 & Actinin, alpha 1 & NM_001102 & 3.54 \\
BCAR1 & Breast cancer anti-estrogen resistance 1 & NM_014567 & 8.07 \\
ENAH & Enabled homolog (Drosophila) & NM_1008493 & 15.45 \\
RASA1 & RAS p21 protein activator 1 & NM_002890 & 2.06 \\
VASP & Vasodilator-stimulated phosphoprotein & NM_003370 & 3.13 \\
VCL & Vinculin & NM_003373 & 4.61
\end{tabular}

Cell projection

$\begin{array}{ll}\text { ACTN4 } & \text { Actinin, alpha } 4 \\ \text { CTTN } & \text { Cortactin } \\ \text { DIAPH1 } & \text { Diaphanous homolog } 1 \\ \text { RDX } & \text { Radixin } \\ \text { RHOB } & \text { Ras homolog gene family, member B } \\ \text { RHOC } & \text { Ras homolog gene family, member C } \\ \text { SVIL } & \text { Supervillin } \\ \text { SRC } & \text { V-src sarcoma viral oncogene homolog }\end{array}$

NM_004924 3.49

NM_005231 5.92

NM_005219 4.74

NM_002906 4.42

NM_004040 3.15

NM_175744 3.44

NM_003174 6.57

NM_005417 4.79

\section{Chemotaxis \\ EGFR Epidermal growth factor receptor \\ ITGB3 Integrin, beta 3 (antigen CD61) \\ LIMK1 LIM domain kinase 1 \\ MYH9 Myosin, heavy chain 9, non-muscle \\ PAK1 P21 protein (Cdc42/Rac)-activated kinase 1 \\ PAK4 P21 protein (Cdc42/Rac)-activated kinase 4 \\ PLCG1 Phospholipase C, gamma 1 \\ PRKCA Protein kinase C, alpha \\ TGF $\beta 1$ Transforming growth factor, beta 1 \\ VEGFA Vascular endothelial growth factor $\mathrm{A}$}

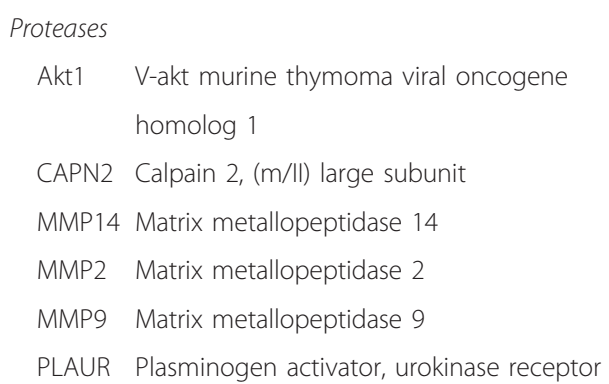

$\begin{array}{ll}\text { NM_005163 } & 3.17 \\ \text { NM_001748 } & 4.49 \\ \text { NM_004995 } & 3.47 \\ \text { NM_004530 } & 5.40 \\ \text { NM_004994 } & 3.68 \\ \text { NM_002659 } & 4.14\end{array}$

according to the manufacturer's instructions. Transient transfected cells were evaluated for expression levels and functional assays.

\section{Adhesion Assay}

Cells with transfection of siRNAs or scrambled control were incubated for $24 \mathrm{~h}$ were harvested and employed for cell adhesion assays (CBA-052, Cell Biolabs, CA, USA). Fortyeight-well plates were coated with collagen I or BSA, and 50000 cells in $150 \mu \mathrm{l}$ of serum-free RPMI 1640 medium were seeded into each well. The plates were incubated at $37^{\circ} \mathrm{C}$ for $1 \mathrm{~h}$, followed by aspiration of the medium and washing by PBS to remove the non-adhesive cells. The wells were stained with cell stain solution for $10 \mathrm{~min}$. The adhesive stained cells were photo-captured. the stained cells were extracted by the extraction solution. Finally, extracted samples were transferred to a 96 -well plate and measured the OD $570 \mathrm{~nm}$ by a microplate photometer.

\section{Migration Assay and Invasion Assay}

Cells transfected with siRNAs or scrambled controls (24- h incubation) were harvested and suspended in RPMI 1640 medium. A transwell culture insert with $8 \mu \mathrm{m}$ pore size membrane for 24-well plate (Cat no. 353097, Falcon, NY, USA) was used to analyze the migration activity. A total of 30000 suspension of cells in $300 \mu$ l of serum-free RPMI 1640 medium were seeded into the upper inserted chamber, $700 \mu \mathrm{l}$ of RPMI containing 10\% FBS were added to the well, and the plate was incubated at $37^{\circ} \mathrm{C}$ for $24 \mathrm{~h}$. After incubation, the inner wall of the chamber was wiped with swabs to remove non-migrating cells. The outer wall of the chamber was gently rinsed with PBS and stained with Crystal Violet (SigmaAldrich, St Louis, MO) for $10 \mathrm{~min}$. Finally, the membrane was rinsed and allowed to air-dry. The stained membrane was photographed and the number of migrated cells was counted.

Invasion assays were performed with a modified migration assay, described above, using Matrigel-coated transwell chambers with $8 \mu \mathrm{m}$ pore size membranes in 24 -well plates (Corning, NY, USA). A total of 30000 cells in $300 \mu \mathrm{l}$ serumfree RPMI 1640 were seeded onto the Matrigel over the upper chamber, followed by the addition of $700 \mu \mathrm{l}$ of RPMI containing $10 \%$ FBS at the bottom insert-well. After incubation of the cells at $37^{\circ} \mathrm{C}$ for $48 \mathrm{~h}$, the following steps were performed as the same of migration assay.

\section{Statistical Analysis}

Statistical analysis was carried out using Statistical Package for Social Sciences (SPSS) 16.0 for Windows (SPSS, Chicago, IL, USA). Student's $t$-test was used to analyze the results expressed as mean \pm s.d. Wilcoxon sign rank test was used to analyze ACTN4 in upregulation of GC. All $P$-values are two-sided and a value of $P \leq 0.05$ is considered statistically significant. 


\section{RESULTS}

\section{Human Cell Motility in GC Tissue Samples}

$\mathrm{RT}^{2}$ Profiler PCR Array for Human Cell Motility was performed in a pair of tumor and non-tumor tissue samples from the same patient with GC (stage IV with metastasis, T3N3M1). Expression of 84 genes were evaluated from this PCR array. Gene expression was normalized to internal controls of GAPDH and $\beta$-actin. Upon comparison of expression patterns in the tissue samples, a panel of dysregulated genes was revealed. An average of a twofold difference in expression was chosen as the cutoff point. Thirty upregulated genes were found in this PCR array (Table 1). Among these genes, several of them are consistent with previous studies, such as Ras associated genes-RhoB and RhoC, EGFR, TGF- $\beta$, Akt, and MMP9. Remarkably, we also found a number of the upregulated genes have never been reported as associated with GC before, including ACTN4, BCAR1, CAPN2, DIAPH1, PLCG1, and RASA1.These results suggest that there are a diverse panel of genes that may play significant roles in GC metastasis.

\section{Expression of Genes in Tissue Samples and Cell Lines}

Expression of the selected genes was evaluated in 10 pairs of gastric tumor/non-tumor tissue samples and six GC cell lines via $\mathrm{qPCR}$. The tissue samples were collected from patients in stage III or stage IV with metastasis. The values (of $y$ axis) in
Figure 1a represent the ratios of expression of genes in tumor tissue samples to the paired non-tumor tissue samples. Values above 1 represent that the gene's expression in tumor tissue samples is higher than that in the paired non-tumor tissue samples, and the number indicates upregulation of each gene in these 10 samples. The qPCR result indicates that ACTN4, BCAR1, CAPN2, DIAPH1, PLCG1, and RASA1 are upregulated in $6 / 10,3 / 10,4 / 10,4 / 10,6 / 10$, and $4 / 10$ pairs of gastric tissue samples (Figure 1a).

In addition to tissue samples, gene expression was also evaluated in GC cell lines. The cell lines used are as follows: MKN7, which was established from a GC metastasizing to lymph nodes; and MKN45 and NCI-N87, established from GC metastasizing to liver. These sites are favored for metastasis of GC. QPCR results show that ACTN4, DIAPH1, PLCG1, and RASA1 are upregulated in 5/6, 2/6, 4/6, and 4/6 GC cell lines compared with commercial normal stomach tissue (CR561840, Origene, MD, USA) (Figure 1b). As ACTN4 is upregulated in 6 out of 10 pairs of tissue samples and 5 out of 6 cancer cell lines, we focused on ACTN4 for further investigation.

\section{Actn4 is Upregulated in GC Tissue Samples and Cell Lines}

To validate upregulation of ACTN4 in GC, we evaluated the expression of ACTN4 in 47 pairs of tissue samples. The
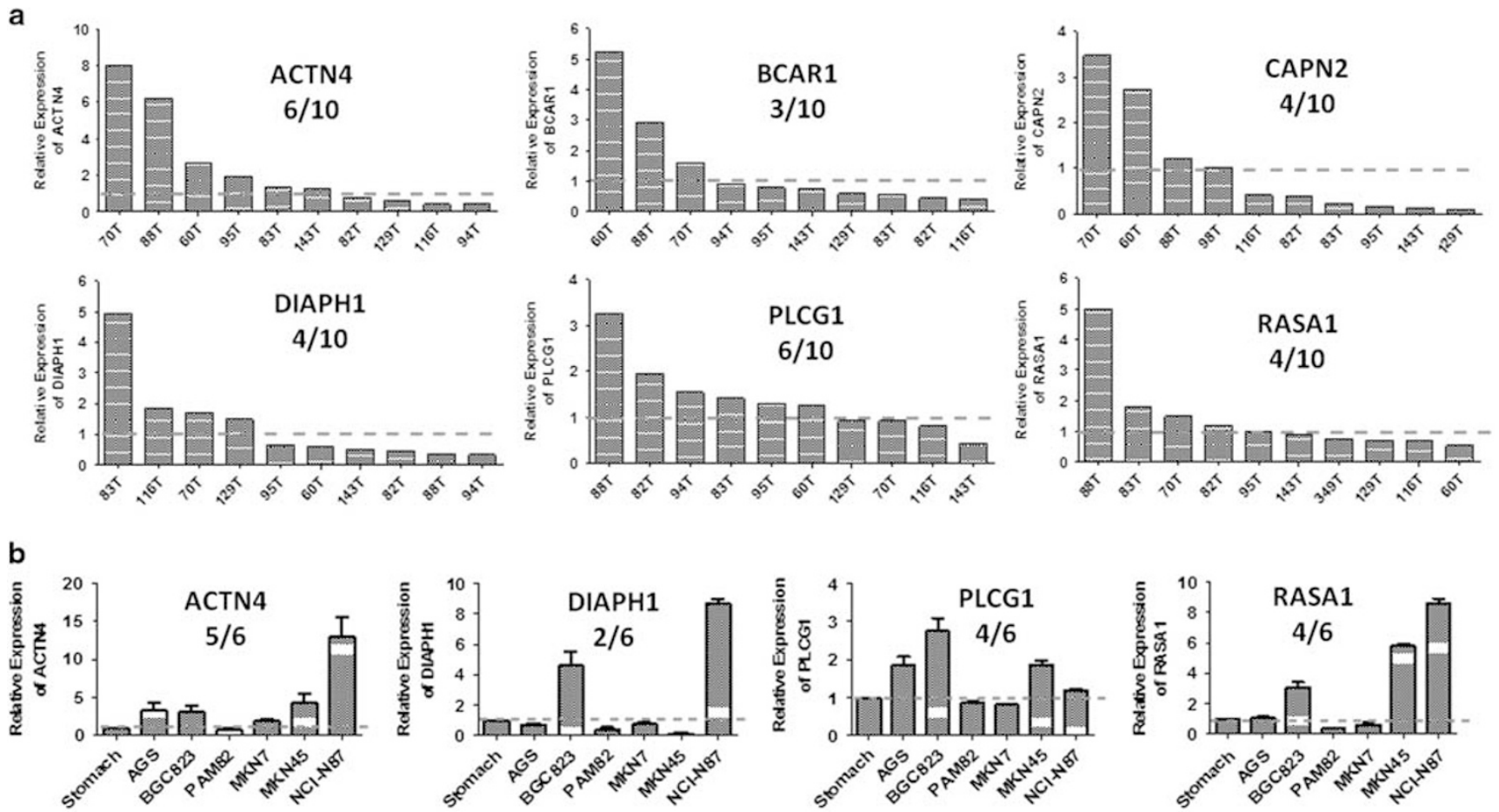

Figure 1 Expression of upregulated genes in human gastric cancer tissue samples and cell lines. Expression of selected genes was evaluated in 10 pairs of stage III or stage IV gastric cancer tissue samples and six gastric cancer cell lines via qPCR. (a) QPCR indicates that ACTN4, BCAR1, CAPN2, DIAPH1, PLCG1, and RASA1 are upregulated in 6/10, 3/10, 4/10, 4/10,6/10, and 4/10 pairs of tissue samples. (b). ACTN4, DIAPH1, PLCG1, and RASA1 are upregulated in $5 / 6,2 / 6,4 / 6$, and $4 / 6$ gastric cancer cell lines comparing with commercial normal stomach tissue. 
Table 2 Clinical characteristics of the subjects in this study

\begin{tabular}{|c|c|}
\hline Characteristics & GC patients $(N=47)$ \\
\hline \multicolumn{2}{|l|}{ Age (years) } \\
\hline Mean (range) & $66(36-89)$ \\
\hline Median & 67 \\
\hline \multicolumn{2}{|l|}{ Gender } \\
\hline Male & 30 \\
\hline Female & 17 \\
\hline \multicolumn{2}{|c|}{ Lauren classification } \\
\hline Intestinal & 23 \\
\hline Diffuse & 15 \\
\hline Intermediate & 2 \\
\hline Not Specified & 7 \\
\hline \multicolumn{2}{|l|}{ Differentiation } \\
\hline Well & 0 \\
\hline Moderate & 16 \\
\hline Poor & 27 \\
\hline Not Specified & 4 \\
\hline \multicolumn{2}{|l|}{ TNM stages } \\
\hline I & 8 \\
\hline$\|$ & 7 \\
\hline III & 16 \\
\hline IV & 16 \\
\hline
\end{tabular}

clinical characteristics of these patients are listed in Table 2. QPCR results indicate that ACTN4 is upregulated in 22 out of 32 GC tissue samples in advanced stage III and IV with metastasis $\left({ }^{*} P=0.0069\right)$, whereas it is upregulated in 4 out of 15 samples in early stage I and II $(P=0.4212)$ (Figure $2 a)$. Overexpression of ACTN4 in GC cell lines was also validated at protein level, except for in BGC823 cells (Figure 2b). This may be attributed to the post-transcriptional regulation of ACTN4 in this cell line. As MKN7, MKN45, and NCI-N87 are established from GC metastasizing to favorite sites lymph node and liver, the result suggests that ACTN4 is significantly overexpressed in metastatic GC.

The above data suggest that ACTN4 is overexpressed in advanced stage of GC tissue samples. Immunohistochemical analysis of ACTN4 expression in these samples was also employed to verify that the high expression of ACTN4 is intrinsic to cancer cells. ACTN4 expression in FFPE samples was detected by immunohistochemistry, which shows that ACTN4 is expressed in cancer cells (Figure 3, arrows indicated). ACTN4 stain was also found in several adjacent non-tumor tissue samples (Supplementary Figure 2). This result is consistent with the qRT-PCR analysis (Figure 2).

\section{Knockdown of Actn4 in GC Cells}

As ACTN4 is overexpressed in GC, knockdown of ACTN4 was performed in GC cells with specific siRNAs (TriFECTa RNAi Kit, IDT). The red fluorescent signal indicates that the percentage of transfection of siRNAs in GC cells reaches over 90\% in AGS, MKN7, and NCI-N87 (Figure 4a). At both the mRNA and protein levels, expression of ACTN4 is significantly decreased in these cell lines $72 \mathrm{~h}$ after knockdown (Figures $4 \mathrm{~b}$ and c). As $\mathrm{qPCR}$ is a very sensitive analytic method, it appears that there is a difference between the expression levels of mRNA and protein with knockdown of ACTN4 in AGS and NCI-N87 cells. But both sets of data indicate that ACTN4 is significantly downregulated by specific siRNAs in these cells. The cells with knockdown of ACTN4 were analyzed in functional assays.

\section{Downregulation of Actn4 Enhances GC Cell Adhesion}

Cell adhesion assay results with AGS, MKN7, and NCI-N87 cells are shown in Figure 5a. Cells did not adhere to plates treated with BSA (data not shown). Relative OD values are indicated in Figure 5b. The result reveals that knockdown of ACTN4 enhances GC cell-matrix adhesion by $40-100 \%$ $\left({ }^{\star} P<0.05,{ }^{*} P<0.01\right)$. From these data, we conclude that the overexpression of ACTN4 inhibits cell adhesion and contributes to cell migration.

\section{Downregulation of Actn4 Suppresses Migration and Invasion of GC Cells}

To further validate that ACTN4 enhances GC metastasis, we employed a transwell migration assay with AGS, MKN7, and NCI-N87 cells that overexpress ACTN4. The cells that had migrated were stained and were counted by microscopy. Representative images of stained cells with scrambled control or siRNAs for ACTN4 are shown in Figure 6a. Relative cell numbers are indicated in Figure $6 \mathrm{~b}$. The migration assay reveals that migrated GC cells are significantly decreased by $40-60 \%$ with reduction of ACTN4 $\left({ }^{* *} P<0.01\right)$.

For invasion assay, the transwell chambers were coated with Matrigel to mimic the basement membrane in the tumor microenvironment. The invasion assay also reveals that the invasiveness of GC cells are significantly decreased by knockdown of ACTN4 in AGS and MKN7 cells by $\sim 40$ $50 \%$ (Figures $7 \mathrm{a}$ and $\mathrm{b}$ ), ${ }^{* *} P<0.01$. The above data indicate that the upregulation of ACTN4 promotes GC cell migration and invasion.

\section{Nf- $\kappa b$ is Decreased in GC Cells and Tissue Samples with Downregulation of Actn4}

To explore the mechanism of ACTN4 promotion of metastasis of GC, we evaluated the expression of its potential targets in GC cells and tissue samples. We found that the 

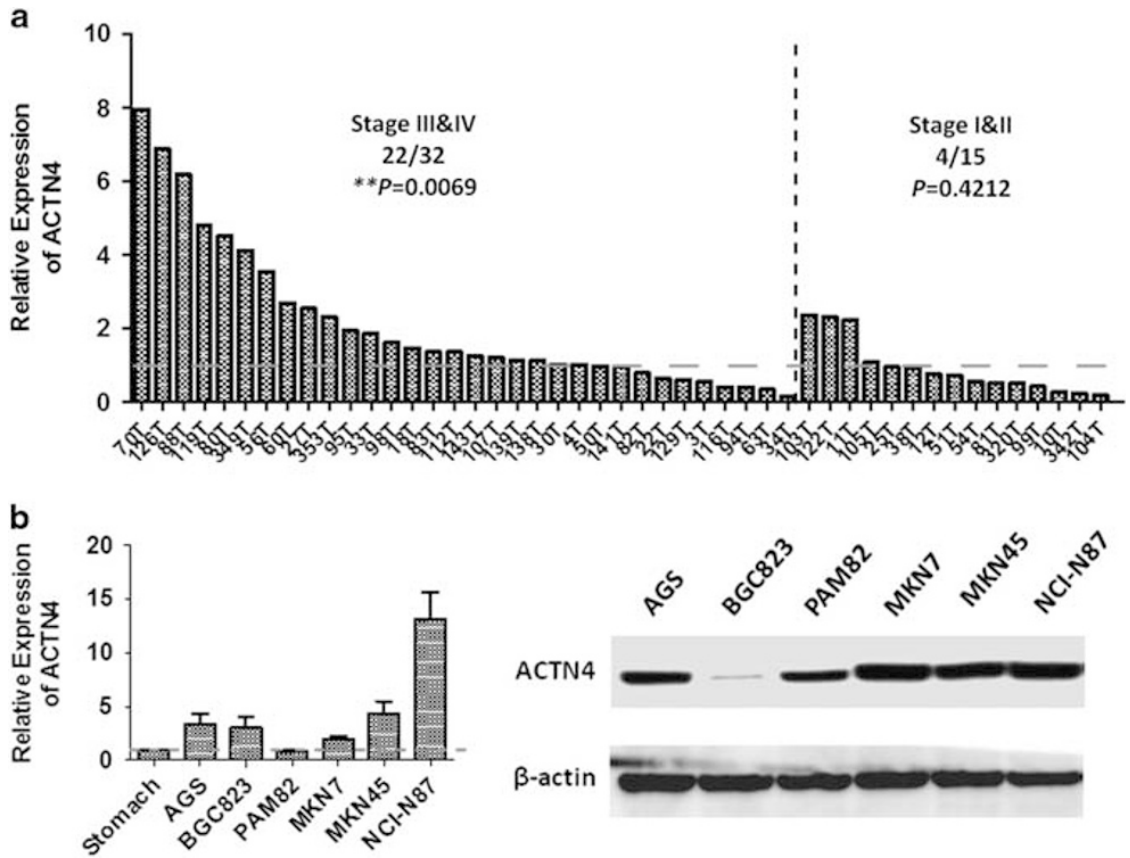

Figure 2 ACTN4 is overexpressed in human gastric cancer tissue samples and cell lines. (a) QPCR indicates that ACTN4 is upregulated in 22 out of 32 pairs of gastric cancer tissue samples in advanced stage III and IV with metastasis ( ${ }^{* *} P=0.0069$ ), whereas it is upregulated in 4 out of 15 pairs of samples in early stage I and II $(P=0.4212)$. (b) Overexpression of ACTN4 in gastric cancer cell lines is validated in protein level.

$27 \mathrm{~T}$

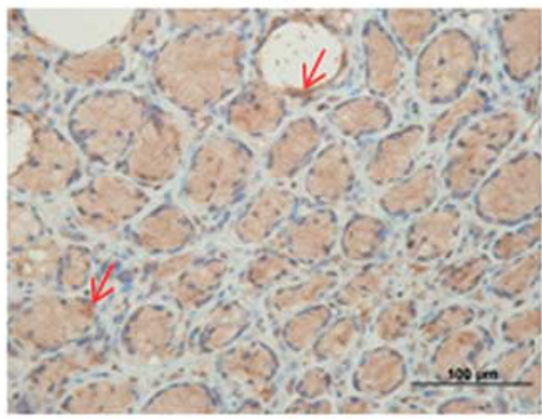

$103 \mathrm{~T}$

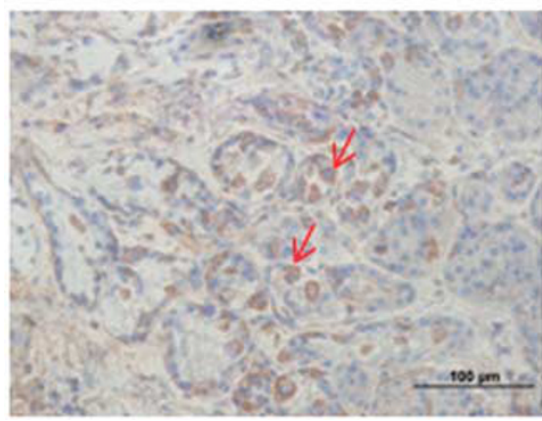

$70 \mathrm{~T}$

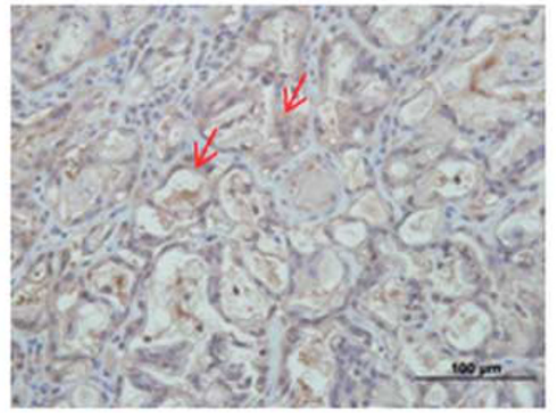

$349 \mathrm{~T}$

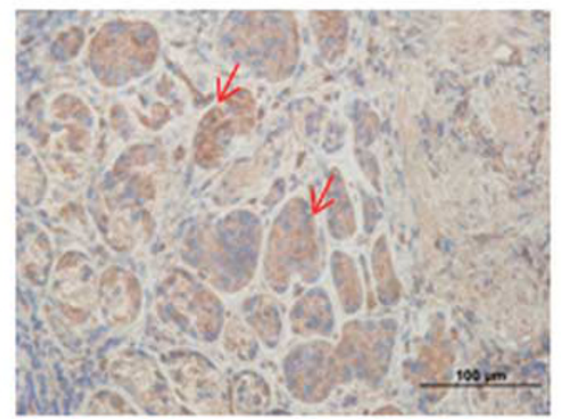

$80 \mathrm{~T}$

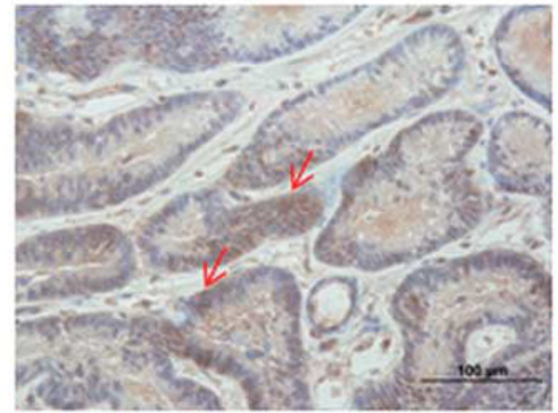

$353 \mathrm{~T}$

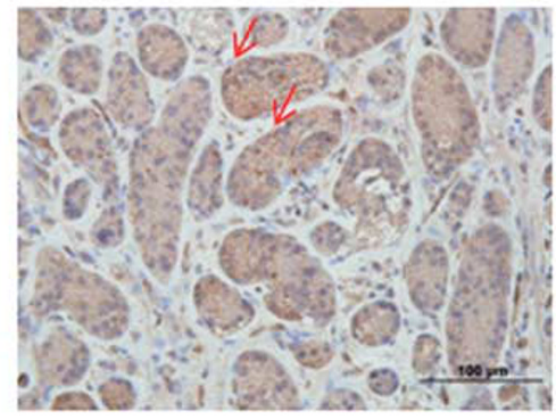

Figure 3 Immunohistochemical analysis of ACTN4 expression in tissue samples of gastric cancer patients. Representative images of the ACTN4 protein immunoreactivity of gastric cancer tissue samples, under a light microscope ( $\times 400$ magnification). Tissue samples were stained with ACTN4-specific antibody as indicated. Cytoplasmic staining with ACTN4 antibody was detected (ACTN4-brown; nuclear DNA-hematoxylin \& eosin). Arrows indicate high expression of ACTN4. 
a
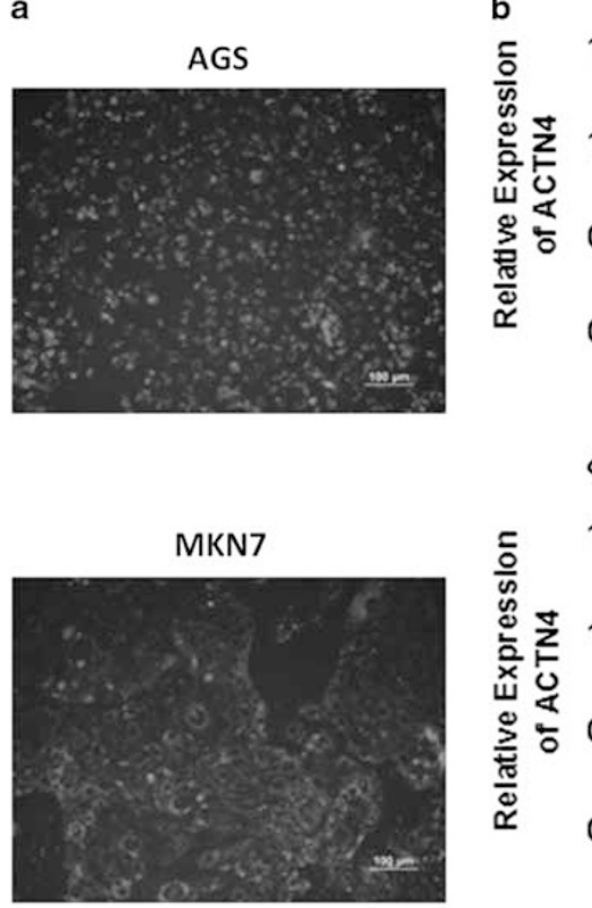

AGS

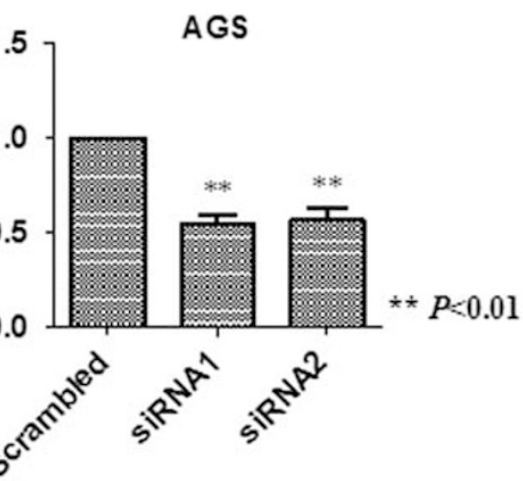

MKN7
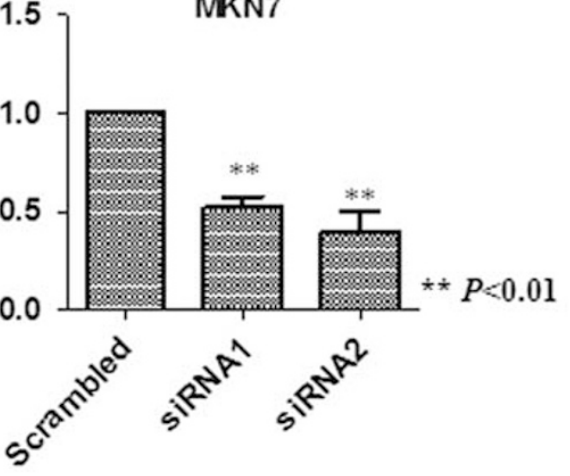

c
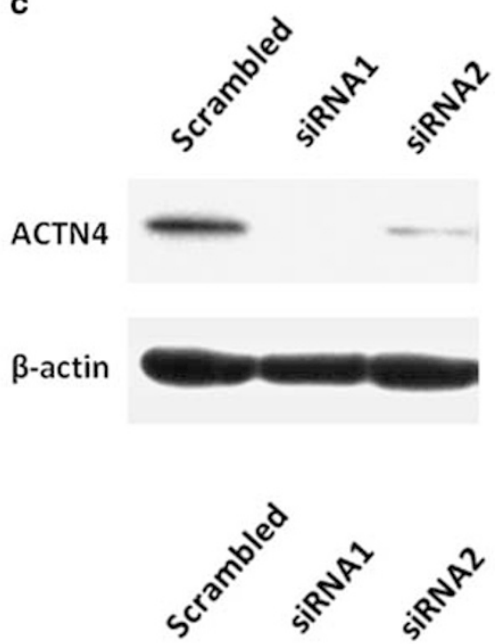

ACTN4

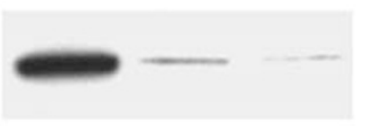

$\beta$-actin
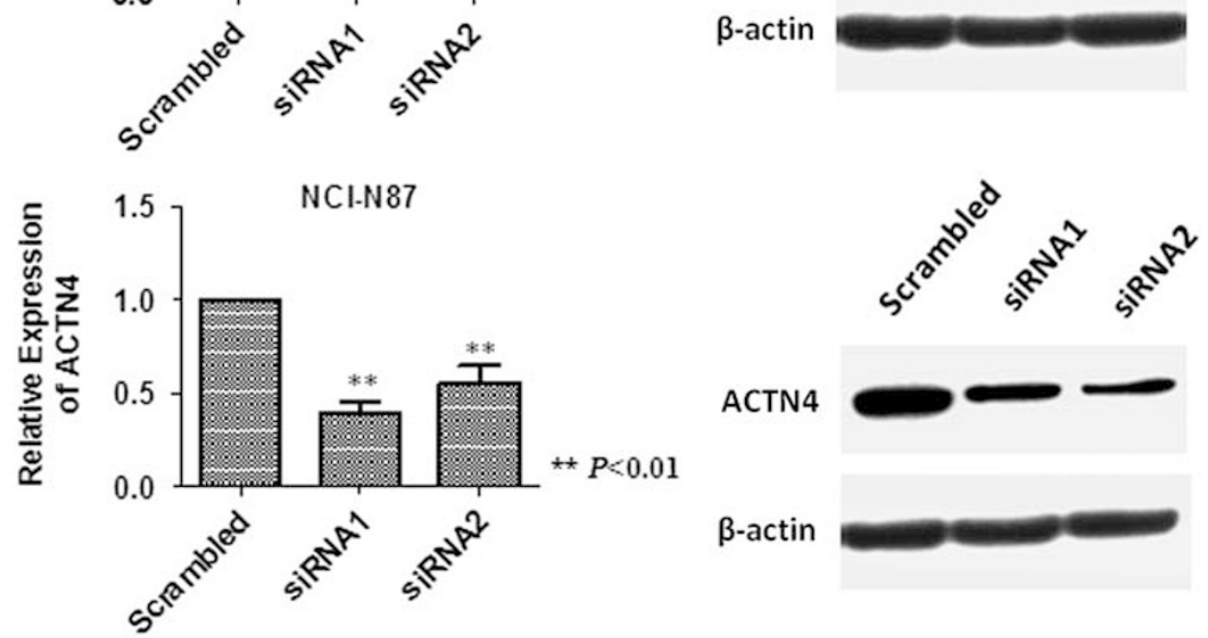

Figure 4 Knockdown of ACTN4 in gastric cancer cells. Knockdown of ACTN4 was performed in gastric cancer cells with specific siRNAs. (a) Fluorescent signal indicates that the percentage of transfection reached more than $90 \%$ in AGS, MKN7, and NCI-N87 cells. (b and c) Both mRNA and protein level indicate that expression of ACTN4 is significantly decreased in three cell lines after knockdown of $72 \mathrm{~h}$.

subunit NF- $\kappa \mathrm{B}$ p50 is significantly downregulated in AGS and NCI-N87 cells, and p65 is downregulated in AGS and MKN7 cells, with knockdown of ACTN4 (Figure 8a), ${ }^{\star} P<0.05$, ${ }^{*} P<0.01$. Further analyses of expression of ACTN4 and $\mathrm{NF}-\kappa \mathrm{B}$ p50 in GC tissue samples indicate that the downregulation of ACTN4 is correlated with decrease of NF- $\kappa B$ p50, especially in stage III and IV samples (Figure $8 \mathrm{~b}$ ). Previous studies have demonstrated that NF- $\kappa \mathrm{B}$ has a significant role in development and progression of GC, and is associated with prognosis. These data suggest that ACTN4 may regulate NF- $\kappa \mathrm{B}$ to promote metastasis of GC.

\section{DISCUSSION}

Metastasis is the most malignant characteristic of cancer. It accounts for cancer mortality and remains as a major challenge in cancer management. ${ }^{28}$ For GC, the 5-year survival rate is $<25 \%$ for patients with advanced stage with metastasis, compared with a $>90 \%$ survival rate for patients in early stages without metastasis. Hence, there is an urgent need to elucidate the mechanism of metastasis in order to overcome chemoresistance and to provide better prognosis for patients with GC.

Cancer metastasis is a complicated, multi-step process. Acquisition of metastatic characteristics by cancer cells induces chemoresistance and further leads to the mortality rate of this disease. To acquire metastatic capability, GC cells interact with tumor microenvironment. The transformed cells receive signals to invade the basement membrane, escape from their original location, move and survive throughout circulation, extravasate, and finally colonize at distant sites. ${ }^{29}$ 
a

AGS

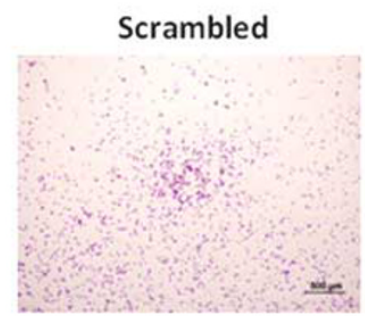

Scrambled

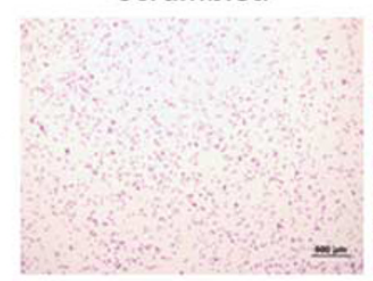

Scrambled
SiRNA1

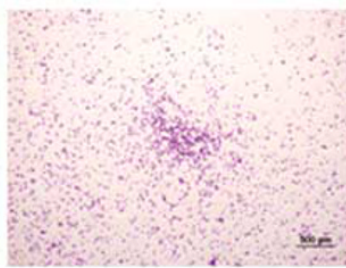

SiRNA1

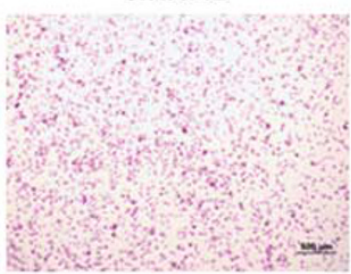

SiRNA1
SiRNA2

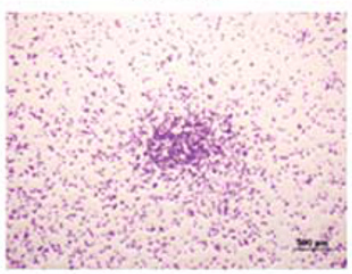

SiRNA2

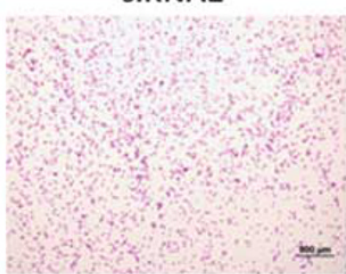

SiRNA2
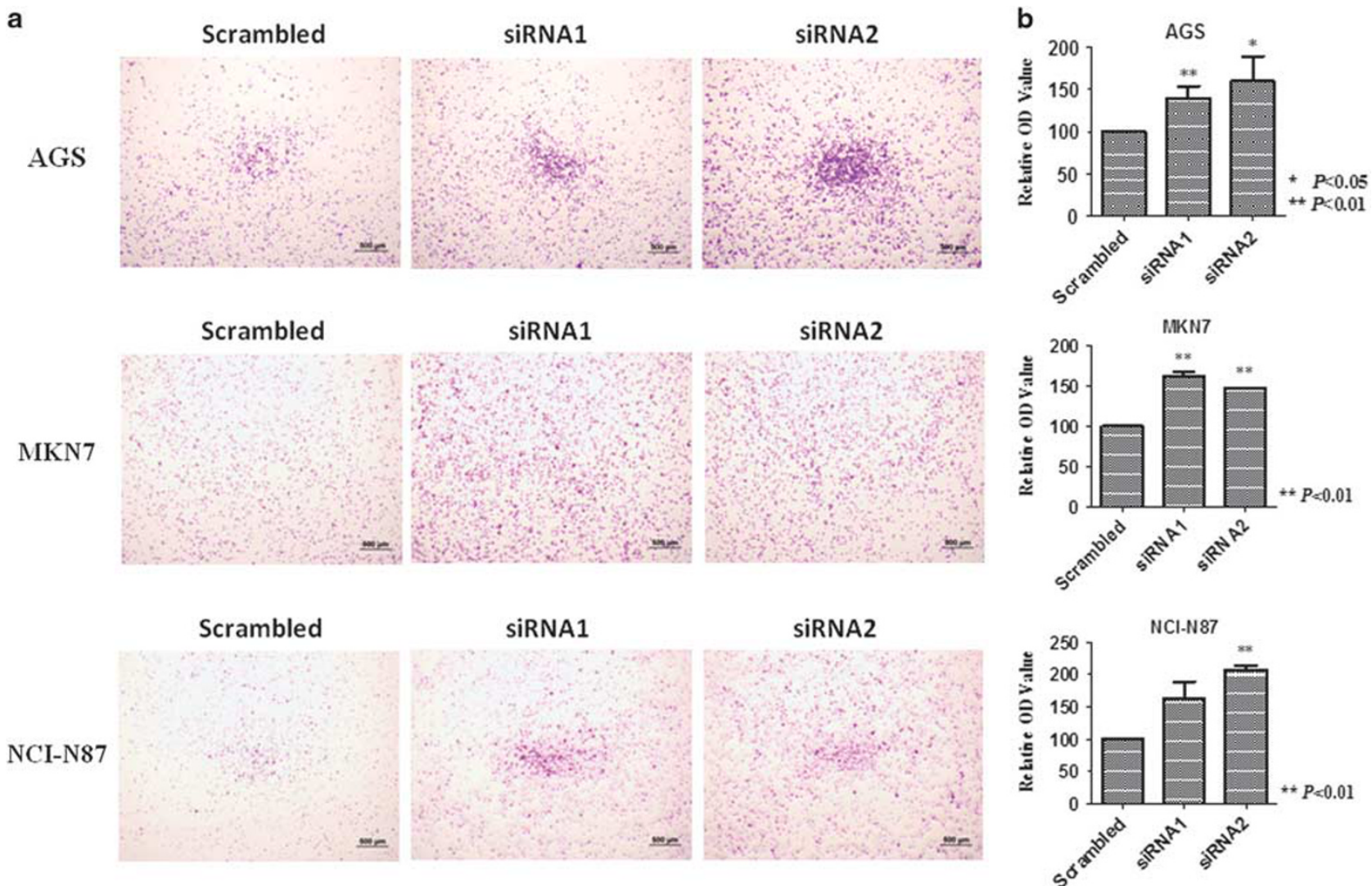

Figure 5 Inhibition of ACTN4 enhances cell adhesion in gastric cancer cells. (a) Representative images of stained adhesive AGS, MKN7, and NCI-N87 cells to collagen I are shown. (b) Stained cells were extracted and measured by microplate photometer. Relative OD values are indicated. The results are shown in mean \pm s.d. ${ }^{*} P<0.05,{ }^{* *} P<0.01$.

Decreased cell-cell or cell-matrix adhesion and increased migratory capability have critical roles in metastasis of GC. We proposed that genes associated with cell adhesion and motility played significant roles in the process of metastasis.

In this study, we found a number of genes differentially expressed in tumor tissue samples compared with paired nontumor tissue samples in patients with GC. It is the first study to demonstrate that ACTN4 has a significant role in metastasis of GC. Upregulation of ACTN4 is also observed in GC cell lines from favorite metastatic sites of lymph nodes (MKN7) and liver (MKN45 and NCI-N87). Cancer metastasis to these sites is associated with poor prognosis. ${ }^{30-32} \mathrm{In}$ addition, ACTN4 does not have significant effect on GC cell proliferation in MTT assay (Supplementary Figure 1), which may be attributed to ACTN4 is not upregulated in early stage of GC. This finding suggests that overexpression of ACTN4 in advanced stages of GC is crucial to metastasis. The data in this study validate the hypothesis that ACTN4 suppresses cell adhesion, promotes cell invasion and increases cell migration of GC and contributes to metastasis of GC.

We also explored the potential mechanism of overexpression of ACTN4 and its functions in GC development. Previous studies indicate that the copy number of ACTN4 increases in lung cancer, pancreatic cancer, and ovarian cancer. ${ }^{26,33,34}$ Moreover, amplification of chromosome 19q13, where the ACTN4 gene located, is also reported in GC..$^{35,36}$ This finding suggests that overexpression of ACTN4 in GC may also be attributed to chromosome amplification.

It has been reported that ACTN4 suppresses focal adhesion maturation in colorectal cancer. ${ }^{37}$ Recruitment of ZYX in focal adhesion is crucial in adhesion maturation and in maintaining the stability of cell adhesion. ${ }^{38-40}$ QPCR indicates that mRNA of ZYX is not regulated by knockdown of ACTN4 (data not shown). These results suggest that ACTN4 may regulate ZYX post-transcriptionally. Whether ACTN4 suppresses focal adhesion through ZYX in GC should be further investigated. Another study indicates that increase of $\beta$-catenin and actinin- 4 is observed in colorectal cancer cells (CRC) with downregulation of E-cadherin. Inhibition of E-cadherin induces $\beta$-catenin and actinin-4 proteins into the membrane protrusions of CRC cells. ${ }^{41}$ It has also been shown that reduction of E-cadherin is associated with high expression of actinin- 4 in ovarian cancer patients. ${ }^{42}$ These results suggest that upregulation of actinin-4 may also be attributed to downregulation of E-cadherin. As loss of E-cadherin is seen in diffuse-type GC, overexpression of ACTN4 in diffuse GC may be associated with downregulation of E-cadherin. Other studies reveal that ACTN4 is a 
a

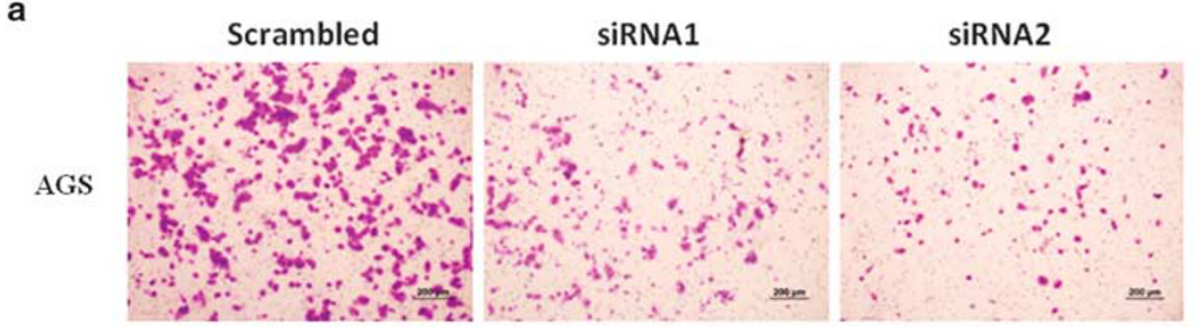

Scrambled

MKN7

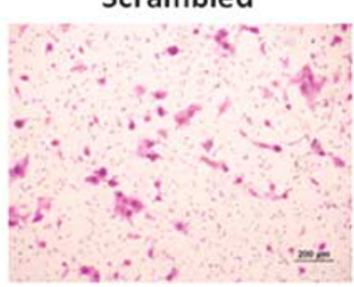

Scrambled

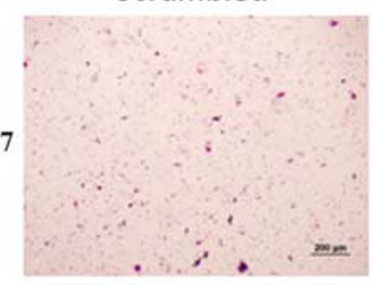

SIRNA1
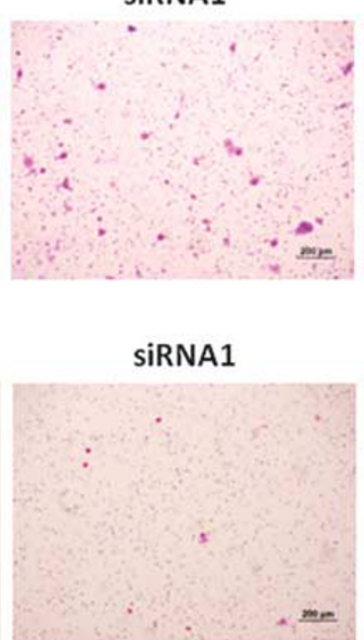

siRNA1
SIRNA2

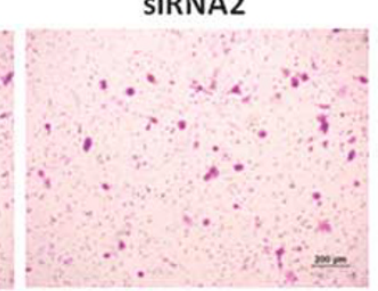

SIRNA2

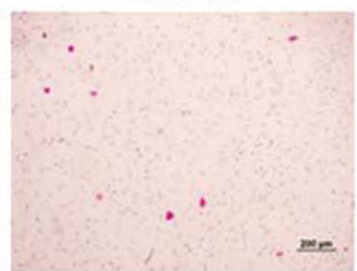

b
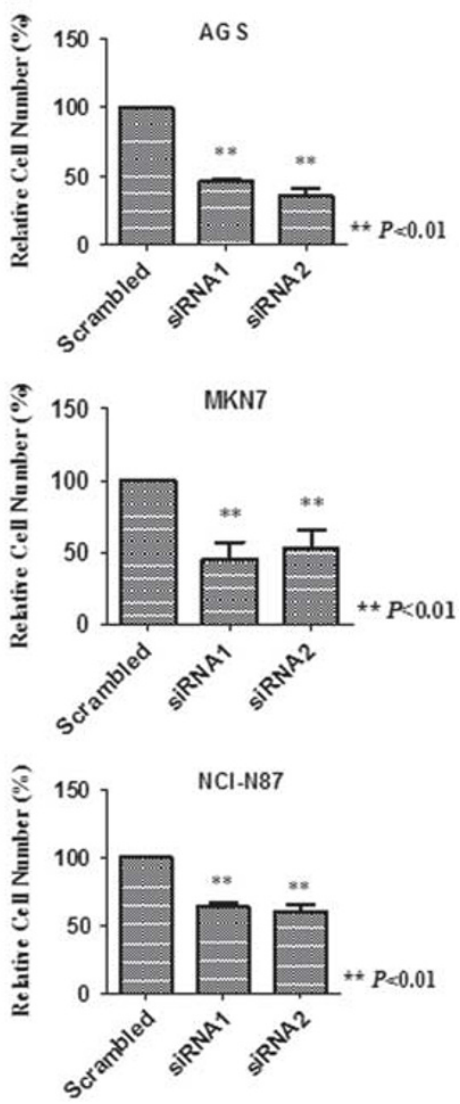

Figure 6 Inhibition of ACTN4 suppresses migration of gastric cancer cells. Transwell migration assay of AGS, MKN7 and NCI-N87 cells. (a) The representative images of stained migrated cells with scrambled control or siRNAs of ACTN4 are shown. (b) The relative numbers of migrated cells are indicated. The ratios are shown in mean \pm s.d. ${ }^{* *} P<0.01$.

a

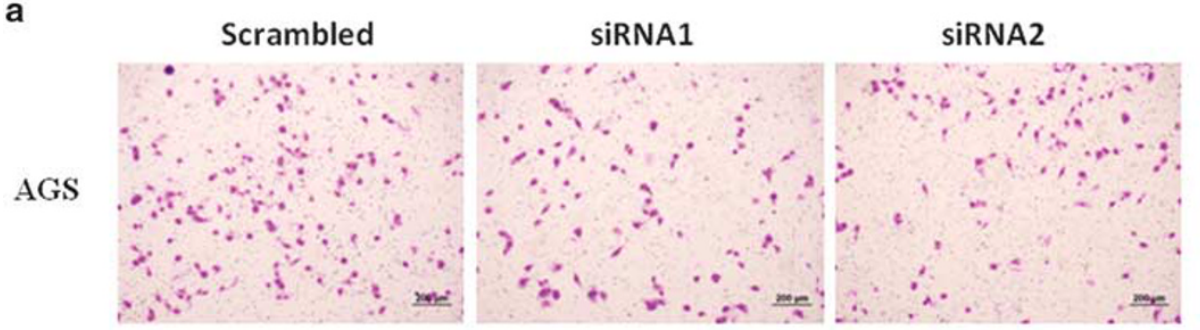

Scrambled

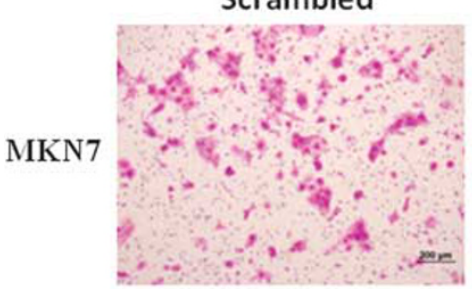

SiRNA1

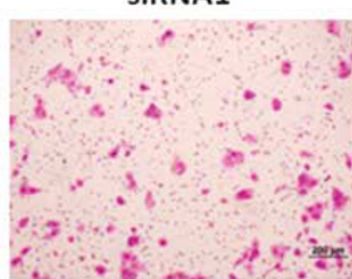

SIRNA2

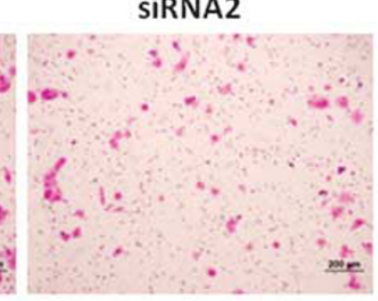

b
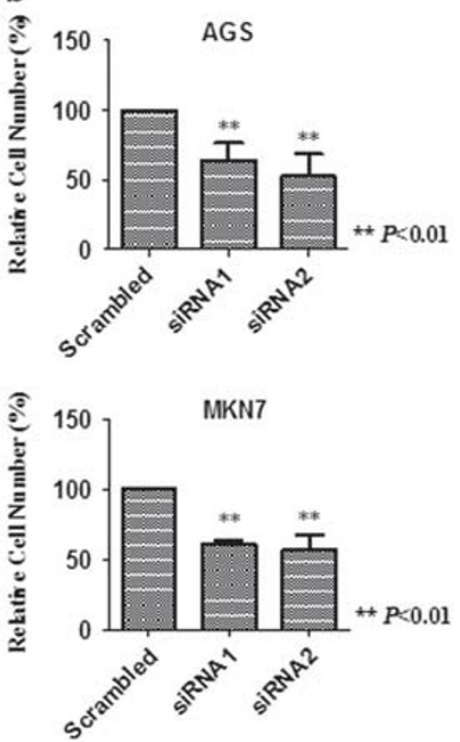

Figure 7 Inhibition of ACTN4 suppresses invasion of gastric cancer cells. Transwell invasion assay of AGS and MKN7 cells. (a) The representative images of stained invasive cells with scrambled control or siRNAs of ACTN4 are shown. (b) The relative numbers of invasive cells are indicated. The ratios are shown in mean \pm s.d. ${ }^{*} P<0.01$. 

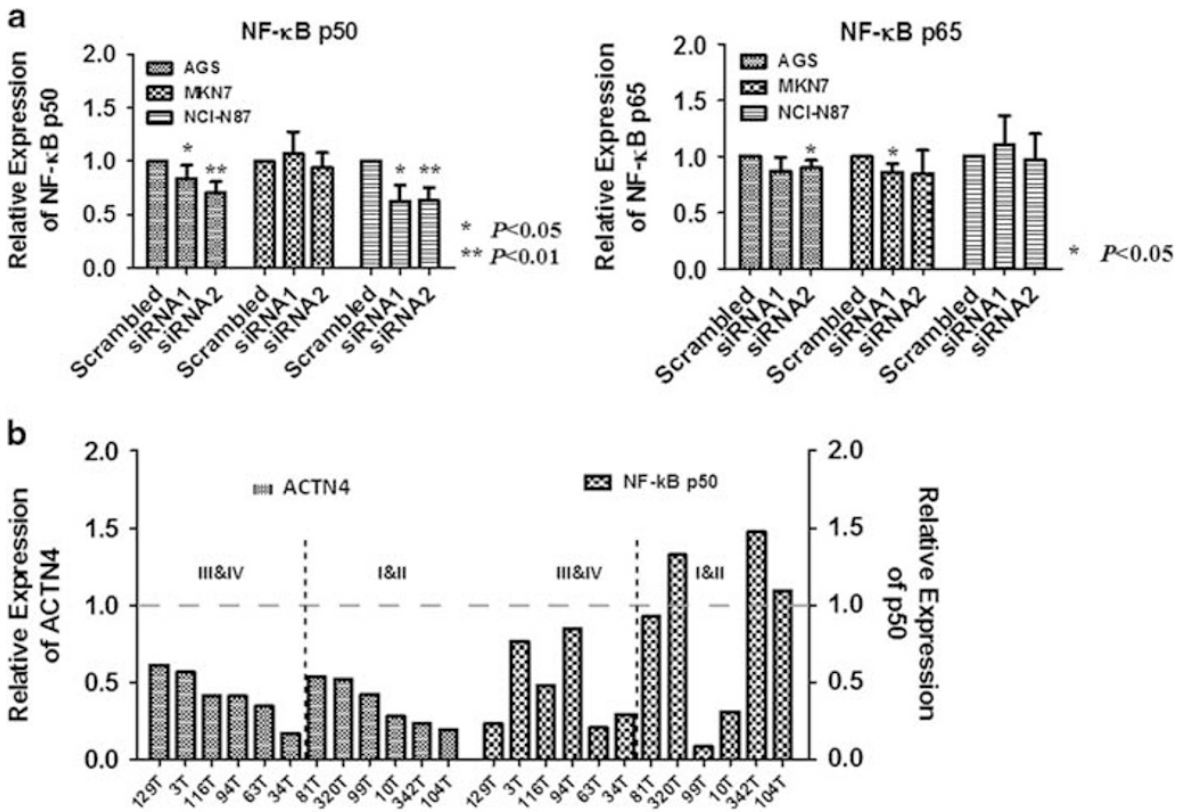

Figure 8 Expression of NF-KB in gastric cancer cells and clinical tissue samples with downregulation of ACTN4. (a) Expression of NF-kB in AGS, MKN7, and NCI-N87 cells with knockdown of ACTN4 via qPCR is indicated. ${ }^{*} P<0.05,{ }^{*} P<0.01$. (b) Expression of ACTN4 and NF-KB p50 in clinical tissue samples are shown. The values indicate the relative expression of genes in tumor tissue samples with respective to their paired adjacent non-tumor tissue samples.

downstream target of PI3K/Akt pathway, ACTN4 regulates RhoA and promotes expression of NF- $\kappa \mathrm{B} .{ }^{43-46}$ It is known that PI3K/Akt pathway is crucial in the development of drug resistance. ${ }^{47-49}$ Drug resistance is a serious consequence of cancer cell metastasis. As a result, targeting ACTN4 not only inhibits metastasis, but also suppresses chemoresistance. In addition, we find that $\mathrm{p} 50$ and $\mathrm{p} 65$, subunits of NF- $\kappa \mathrm{B}$, are downregulated in GC cells with knockdown of ACTN4. This finding suggests that ACTN4 may regulate NF- $\kappa$ B in GC. Previous studies indicate that ACTN4 functions as a transcriptional co-activator of subunits p50 and p65 of NF$\kappa \mathrm{B}$ in HEK293 and A431 cells. ACTN4 has an important role in nuclear translocation and the functions of NF- $\kappa \mathrm{B} .{ }^{46,50}$ Our study suggests that downregulation of ACTN4 contributes to a decrease in NF- $\kappa$ B p50 in metastatic GC cells and clinical tissue samples, which suggests that downregulation of NF- $\kappa \mathrm{B}$ may partly be attributed to knockdown of ACTN4 in GC. As NF- $\kappa \mathrm{B}$ has critical roles in cancer development including metastasis, ${ }^{51-53}$ decrease of NF- $\kappa$ B via inhibition of ACTN4 may abrogate metastasis of GC. It is believed that ACTN4 interacts with numerous genes and components to regulate signaling pathways leading to metastasis of GC.

In conclusion, this is the first study to reveal that ACTN4 contributes to metastasis of GC by suppressing cell adhesion, enhancing cell invasion, and migration. Elucidation of the mechanism of metastasis may help prevent metastasis in patients who are diagnosed with early cancer lesions, as well as to lead to effective therapies for patients with established metastases. ACTN4 may therefore be a novel therapeutic target for metastatic GC.

Supplementary Information accompanies the paper on the Laboratory Investigation website (http://www.laboratoryinvestigation.org)

\section{ACKNOWLEDGMENTS}

This project was supported by the Small Project Funding for basic research from the University of Hong Kong (201409176102). Sincere thanks are sent to Dr Tammy Pang for technical support of sample preparation and western blot in this study. Sincere thanks are also sent to Mr Leo Wu for language editing of this manuscript.

\section{DISCLOSURE/CONFLICT OF INTEREST}

The authors declare no conflict of interests for this study.

1. Torre LA, Bray F, Siegel RL, et al. Global cancer statistics, 2012. CA Cancer J Clin 2015:65:87-108.

2. Mathers $C D$, Loncar D. Projections of global mortality and burden of disease from 2002 to 2030. PLoS Med 2006;3:e442.

3. Leung WK, Wu MS, Kakugawa $Y$, et al. Screening for gastric cancer in Asia: current evidence and practice. Lancet Oncol 2008:9:279-287.

4. Dinis-Ribeiro $M$, Areia $M$, de Vries $A C$, et al. Management of precancerous conditions and lesions in the stomach (MAPS): guideline from the European Society of Gastrointestinal Endoscopy (ESGE), European Helicobacter Study Group (EHSG), European Society of Pathology (ESP), and the Sociedade Portuguesa de Endoscopia Digestiva (SPED). Endoscopy 2012;44:74-94.

5. Kwee RM, Kwee TC. Modern imaging techniques for preoperative detection of distant metastases in gastric cancer. World J Gastroenterol 2015:21:10502-10509.

6. Kim KH, Lee KW, Baek SK, et al. Survival benefit of gastrectomy +/metastasectomy in patients with metastatic gastric cancer receiving chemotherapy. Gastric Cancer 2011;14:130-138. 
7. Valastyan S, Weinberg RA. Tumor metastasis: molecular insights and evolving paradigms. Cell 2011;147:275-292.

8. Zlotnik A, Burkhardt AM, Homey B. Homeostatic chemokine receptors and organ-specific metastasis. Nat Rev Immunol 2011;11:597-606.

9. Wakefield LM, Hill CS. Beyond TGFbeta: roles of other TGFbeta superfamily members in cancer. Nat Rev Cancer 2013;13:328-341.

10. Ebos JM, Kerbel RS. Antiangiogenic therapy: impact on invasion, disease progression, and metastasis. Nat Rev Clin Oncol 2011;8:210-221.

11. Reymond N, d'Agua BB, Ridley AJ. Crossing the endothelial barrier during metastasis. Nat Rev Cancer 2013;13:858-870.

12. Tauro M, McGuire J, Lynch CC. New approaches to selectively target cancer-associated matrix metalloproteinase activity. Cancer Metastasis Rev 2014;33:1043-1057.

13. Lim J, Ryu JH, Kim EJ, et al. Inhibition of vascular endothelial growth factor receptor 3 reduces migration of gastric cancer cells. Cancer Invest 2015;33:398-404.

14. Park, do J, Thomas NJ, Yoon C, et al. Vascular endothelial growth factor a inhibition in gastric cancer. Gastric Cancer 2015;18:33-42.

15. Li W, Li S, Deng L, et al. Decreased MT1-MMP in gastric cance suppressed cell migration and invasion via regulating MMPs and EMT. Tumour Biol 2015;36:6883-6889.

16. Chen SZ, Yao HQ, Zhu SZ, et al. Expression levels of matrix metalloproteinase-9 in human gastric carcinoma. Oncol Lett 2015;9: 915-919.

17. Hao NB, Tang B, Wang GZ, et al. Hepatocyte growth factor (HGF) upregulates heparanase expression via the PI3K/Akt/NF-kappaB signaling pathway for gastric cancer metastasis. Cancer Lett 2015;361:57-66.

18. Liu J, Zhang Y, Xu R, et al. PI3K/Akt-dependent phosphorylation of GSK3beta and activation of RhoA regulate Wnt5a-induced gastric cancer cell migration. Cell Signal 2013;25:447-456.

19. Huang J, Xiao D, Li G, et al. EphA2 promotes epithelial-mesenchymal transition through the Wnt/beta-catenin pathway in gastric cancer cells. Oncogene 2014;33:2737-2747.

20. Hsu KW, Hsieh RH, Huang $\mathrm{KH}$, et al. Activation of the Notch1/STAT3/ Twist signaling axis promotes gastric cancer progression. Carcinogenesis 2012;33:1459-1467.

21. Murphy AC, Young PW. The actinin family of actin cross-linking proteins - a genetic perspective. Cell Biosci 2015;5:49.

22. Ehrlicher AJ, Krishnan $\mathrm{R}, \mathrm{Guo} \mathrm{M}$, et al. Alpha-actinin binding kinetic modulate cellular dynamics and force generation. Proc Natl Acad Sci USA 2015;112:6619-6624.

23. Hamill KJ, Hopkinson SB, Skalli O, et al. Actinin-4 in keratinocytes regulates motility via an effect on lamellipodia stability and matrix adhesions. Faseb J 2013;27:546-556.

24. Feng $\mathrm{Y}, \mathrm{Ngu} \mathrm{H}$, Alford $\mathrm{SK}$, et al. alpha-actinin1 and 4 tyrosine phosphorylation is critical for stress fiber establishment, maintenance and focal adhesion maturation. Exp Cell Res 2013;319:1124-1135.

25. Gao Y, Li G, Sun L, et al. ACTN4 and the pathways associated with cell motility and adhesion contribute to the process of lung cancer metastasis to the brain. BMC Cancer 2015;15:277.

26. Yamamoto $\mathrm{S}$, Tsuda $\mathrm{H}$, Honda $\mathrm{K}$, et al. Actinin-4 gene amplification in ovarian cancer: a candidate oncogene associated with poor patient prognosis and tumor chemoresistance. Mod Pathol 2009;22:499-507.

27. Honda $\mathrm{K}$, Yamada $T$, Hayashida $\mathrm{Y}$, et al. Actinin-4 increases cell motility and promotes lymph node metastasis of colorectal cancer. Gastroenterology 2005;128:51-62.

28. Sethi N, Kang Y. Unravelling the complexity of metastasis - molecular understanding and targeted therapies. Nat Rev Cancer 2011;11:735-748.

29. Sosa MS, Bragado P, Aguirre-Ghiso JA. Mechanisms of disseminated cancer cell dormancy: an awakening field. Nat Rev Cancer 2014;14: 611-622.

30. Ma M, Chen S, Zhu BY, et al. The clinical significance and risk factors of solitary lymph node metastasis in gastric cancer. PLoS One 2015;10: e0114939.

31. Deng JY, Liang $\mathrm{H}$. Clinical significance of lymph node metastasis in gastric cancer. World J Gastroenterol 2014;20:3967-3975.

32. Jin X, Zhu Z, Shi Y. Metastasis mechanism and gene/protein expression in gastric cancer with distant organs metastasis. Bull Cancer 2014;101:E1-E12.
33. Noro $\mathrm{R}$, Honda $\mathrm{K}$, Tsuta $\mathrm{K}$, et al. Distinct outcome of stage I lung adenocarcinoma with ACTN4 cell motility gene amplification. Ann Oncol 2013;24:2594-2600.

34. Watanabe $\mathrm{T}$, Ueno $\mathrm{H}$, Watabe $\mathrm{Y}$, et al. ACTN4 copy number increase as a predictive biomarker for chemoradiotherapy of locally advanced pancreatic cancer. Br J Cancer 2015;112:704-713.

35. Varis $A$, van Rees $B$, Weterman $M$, et al. DNA copy number changes in young gastric cancer patients with special reference to chromosome 19. Br J Cancer 2003;88:1914-1919.

36. van Dekken $\mathrm{H}$, Alers JC, Riegman $\mathrm{PH}$, et al. Molecular cytogenetic evaluation of gastric cardia adenocarcinoma and precursor lesions. Am J Pathol 2001;158:1961-1967.

37. Fukumoto M, Kurisu S, Yamada $T$, et al. alpha-Actinin-4 enhances colorectal cancer cell invasion by suppressing focal adhesion maturation. PLoS One 2015;10:e0120616.

38. Hoffman LM, Jensen CC, Chaturvedi A, et al. Stretch-induced actin remodeling requires targeting of zyxin to stress fibers and recruitment of actin regulators. Mol Biol Cell 2012;23:1846-1859.

39. Gregory Call S, Brereton D, Bullard JT, et al. A zyxin-nectin interaction facilitates zyxin localization to cell-cell adhesions. Biochem Biophys Res Commun 2011;415:485-489.

40. Sun N, Huiatt TW, Paulin D, et al. Synemin interacts with the LIM domain protein zyxin and is essential for cell adhesion and migration. Exp Cell Res 2010;316:491-505.

41. Hayashida $Y$, Honda $K$, Idogawa $M$, et al. E-cadherin regulates the association between beta-catenin and actinin-4. Cancer Res 2005;65: 8836-8845

42. Yamamoto $\mathrm{S}$, Tsuda $\mathrm{H}$, Honda $\mathrm{K}$, et al. Actinin-4 expression in ovarian cancer: a novel prognostic indicator independent of clinical stage and histological type. Mod Pathol 2007;20:1278-1285.

43. Lu Z, Zhang Y, Yan X, et al. Estrogen stimulates the invasion of ovarian cancer cells via activation of the PI3K/AKT pathway and regulation of its downstream targets Ecadherin and alphaactinin4. Mol Med Rep 2014;10:2433-2440.

44. Quick Q, Skalli O. Alpha-actinin 1 and alpha-actinin 4: contrasting roles in the survival, motility, and RhoA signaling of astrocytoma cells. Exp Cell Res 2010;316:1137-1147.

45. Zhao X, Hsu KS, Lim JH, et al. alpha-Actinin 4 potentiates nuclear factor kappa-light-chain-enhancer of activated B-cell (NF-kappaB) activity in podocytes independent of its cytoplasmic actin binding function. J Biol Chem 2015;290:338-349.

46. Aksenova $\mathrm{V}$, Turoverova $\mathrm{L}$, Khotin $\mathrm{M}$, et al. Actin-binding protein alpha-actinin 4 (ACTN4) is a transcriptional co-activator of RelA/p65 sub-unit of NF-kB. Oncotarget 2013;4:362-372.

47. Sukawa $\mathrm{Y}$, Yamamoto $\mathrm{H}$, Nosho $\mathrm{K}$, et al. HER2 expression and PI3K-Akt pathway alterations in gastric cancer. Digestion 2014;89:12-17.

48. Park J, Ko YS, Yoon J, et al. The forkhead transcription factor FOXO1 mediates cisplatin resistance in gastric cancer cells by activating phosphoinositide 3-kinase/Akt pathway. Gastric Cancer 2014;17: 423-430.

49. Yu HG, Ai YW, Yu LL, et al. Phosphoinositide 3-kinase/Akt pathway plays an important role in chemoresistance of gastric cancer cells against etoposide and doxorubicin induced cell death. Int J Cancer 2008;122:433-443.

50. Babakov VN, Petukhova OA, Turoverova LV, et al. RelA/NF-kappaB transcription factor associates with alpha-actinin-4. Exp Cell Res 2008:314:1030-1038.

51. Li J, Deng Z, Wang Z, et al. Zipper-interacting protein kinase promotes epithelial-mesenchymal transition, invasion and metastasis through AKT and NF-kB signaling and is associated with metastasis and poor prognosis in gastric cancer patients. Oncotarget 2015;6:8323-8338.

52. Ma J, Liu J, Wang Z, et al. NF-kappaB-dependent microRNA-425 upregulation promotes gastric cancer cell growth by targeting PTEN upon IL-1 beta induction. Mol Cancer 2014;13:40.

53. Burkitt MD, Williams JM, Duckworth CA, et al. Signaling mediated by the NF-kappaB sub-units NF-kappaB1, NF-kappaB2 and c-Rel differentially regulate Helicobacter felis-induced gastric carcinogenesis in C57BL/6 mice. Oncogene 2013;32:5563-5573. 